\title{
Differences in resistance of three subtropical vegetation types to experimental trampling.
}

Rachel Hill $^{\mathrm{a}}$ and Catherine Pickering ${ }^{\mathrm{a}}$

${ }^{\mathrm{a}}$ School of Environment, Gold Coast Campus, Griffith University, QLD, 4222

\section{AUSTRALIA.}

Corresponding Author: Catherine Pickering

E-mail: c.pickering@griffith.edu.au

Ph: + 61 (0) 75552 8059, Fax: + 61 (0) 755528067

\begin{abstract}
Experimental trampling trials using a standardized methodology were undertaken in ten replicate blocks in three vegetation types in an urban reserve in the subtropics of Australia. In each block different intensities of trampling (controls, 10, 25, 50, 100, 150, 200, 250, 300, 400 and 500 passes) were applied, and vegetation parameters were measured pre trampling, immediately after trampling and two weeks later. A fern understorey had low resistance to trampling intensity, with reductions in relative vegetation height and cover with as few as 10 passes. A tussock grass understorey showed moderate resistance with reduction in height at 25 passes and cover at 50 passes. A disturbed grassland dominated by lawn grasses had the highest resistance, with reductions in vegetation height at 100 passes, but cover was affected by as few as 10 passes. The resistance indices (number of passes required to reduce vegetation cover by 50\%) of three vegetation types were 210, 360 and 860 passes respectively. When these values were compared with those for 52 other vegetation types considerable variation was found within life forms, climatic zones and vegetation types indicating that the response of a specific community may not always be predictable.
\end{abstract}


Keywords: tourism impacts; management; Eucalyptus understorey, recreation ecology

\section{Introduction}

The creation of paths through vegetation is an inherent part of exploration by humans in natural areas (Liddle, 1997). Hence, “trampling” is an important component of human-induced impacts in natural areas (Liddle, 1997; Newsome et al. 2002; Cole, 2004). Although there have been some studies on the impacts of trampling on invertebrates and other animals (Chappell et al. 1971; Duffey, 1975; Liddle, 1997), the majority of trampling studies examined impacts on vegetation and soil (Liddle, 1997; Littlemore and Barker, 2001; Newsome et al. 2002; Cole, 2004; Pickering and Hill 2007). As a result generalisations about the resistance (ability to with stand disturbance before damage occurs), resilience (ability to recover from damage once it occurs) and tolerance (combination of resistance and reliance) of different types of vegetation to trampling have been made (Cole and Bayfield, 1993; Cole, 1995a,b, 2004; Liddle, 1997; Yorks et al. 1997; Tolvanen et al. 2001; Newsome et al. 2002; Monz, 2002). Resistance of vegetation types is affected by the characteristics of the vegetation and soils (Liddle, 1997; Marion and Cole, 1996; Cole, 1995a,b, 2004). Generally the order of the resistance of life forms is graminoids $>$ trees $>$ forbs >shrubs (Yorks et al. 1997). Grasses and other graminoids are considered more resistant to trampling because they have flexible, horizontal branching stems, narrow leaves, below-ground reproductive structures, low-to-ground growing points and protective sheaths at leaf bases (Sun and Liddle, 1993; Liddle, 1997; Yorks et al. 1997; Tolvanen et al. 2001). In comparison, shrubs, ferns and forbs that have broad leaves, vertical or woody stems, leaves only on the 'above ground' parts and 
reproductive structures high on the plant, are likely to be more sensitive to trampling impacts (Liddle, 1997; Yorks et al. 1997; Tolvanen et al. 2001).

Many studies examining trampling impacts have been conducted in North America and Europe on mountain and temperate vegetation types (Cole, 2004, Table 1). For example, of the 65 vegetation types in which the impacts of trampling have been tested using modifications of a standardized experimental protocol developed by Cole and Bayfield (1993), 44 were in mountains and 11 were in temperate regions. Only two tropical vegetation types in the Wet Tropics of Australia have been tested (Talbot et al. 2003), and there are no studies using this standardized experimental protocol on subtropical vegetation. In three studies in subtropical Eucalyptus forest in Australia that used different methodologies, the resistance of vegetation to trampling was highly variable, and the resistance indices (the number of passes required to reduce vegetation cover by 50\%) ranged from 12 to 1421 passes (Liddle, 1997).

The objectives of this study are to (1) test if generalisations about the resistance of different life-forms to trampling that have principally been based on results from colder climates apply to vegetation in warmer climates such as the subtropics of Australia, and (2) see if the resistance of understorey vegetation was as variable among Australian subtropical vegetation types when trampling methodology was standardized. Manipulative experimental trampling trials were conducted in three vegetation types in an Urban Reserve in the subtropics of Queensland, Australia that were likely to vary in resistance based on the characteristics of the dominant ground cover. A disturbed grassland dominated by a common lawn species, Bermuda grass (Cynodon dactylon) was predicted to show high resistance, a tussock grass understorey dominated by (Imperata cylindrica, Cynodon dactylon and Poa sp.) was predicted to have moderate resistance, and a Bracken Fern (Pteridium esculentum) 
understorey in a Eucalyptus forest was predicted to have low resistance due to the tall woody life form of the fern.

\section{Methods}

\subsection{Description of study area}

Experimental trampling trials were conducted on three vegetation types in a popular urban reserve (Coombabah Lakes Conservation Area, 1,290 hectares) in the northern end of the Gold Coast, (population 550,000) (Fig. 1). Like much of the rest of the coast of south-eastern Australia, the Gold Coast has experienced large scale vegetation clearing, initially for forestry and agriculture, but more recently for urban development. The Coombabah Lakes Conservation Area is the largest remaining area of relatively undisturbed coastal vegetation in the region and it, and associated estuarine system is part of RAMSAR wetlands reflecting its significance as a migratory water bird habitat. The flat to gently sloping reserve consists of forests, woodlands, mangroves, cleared forest with disturbed grassland and freshwater/tidal wetlands. In areas subject to occasional inundation there are paperbark swamps dominated by Melaleuca quinquenervia. On the drier replicates there are woodlands of Eucalyptus pilularis often with a Bracken Fern understorey (Pteridium esculentum). In cleared areas, there is disturbed grassland mostly of the lawn grass Bermuda grass (Cynodon dactylon). This species is considered highly resistant to trampling (Frenkel 1972). The entire area is close to housing and, although no specific figures of usage are available, it has relatively consistent moderate use by small groups of people undertaking various walks in the area, with most people staying on designated tracks (authors. obs.). The grassland area is also frequented by eastern grey kangaroos (Macropus giganteus) for grazing. 


\subsection{Experimental design}

To increase the power of the analyses, a larger number of replicates and intensities of trampling were undertaken than in the original protocol (Cole and Bayfield 1993).

Ten replicate (blocks) were randomly selected from thirty potential suitable blocks in relatively undisturbed areas in each community, without evidence of pre-established tracks, paths or roads (Supplementary material: Location of sites). In each replicate a series of parallel lanes $4 \mathrm{~m}$ long and $50 \mathrm{~cm}$ wide, separated by a narrow $40 \mathrm{~cm}$ access strip, were marked out. Vegetation structure in each replicate was relatively homogenous. Treatments levels (two control lanes, 10, 25, 50, 100, 150, 200, 250, 300, 400 and 500 passes) were randomly assigned to lanes, with one treatment per lane. In the Disturbed grassland an additional 700 pass treatment lane was included in each replicate block given the expected higher resistance of this community. Because a larger number of trampling intensities (lanes) were used than in the standard protocol, an additional control lane was included. A single pass was defined as a walk along the full length of the $4 \mathrm{~m}$ treatment lane by one person (Cole, 1995a). Trampling was undertaken in the winter (dry season) of 2006, when climatic conditions are particularly suitable for walking (cooler and dry). Trampling was undertaken only once with all trampling within a replicate completed on the same day. Vegetation parameters were measured immediately before trampling in control lanes and then in all lanes two weeks post trampling.

A point intercept method was used to measure the maximum height of vegetation using a ruler at 20 points along 2 parallel transects running the full length of each lane. Any detached plant material was considered litter and given a height measurement of zero. Relative height for each lane was then calculated as: Relative Height $=$ mean height of vegetation at 2 weeks in a trampling lane $* c f$ initial mean height of vegetation in the control lane 
Where: $c f$ (control factor) $=$ initial mean height in control lane

2 weeks mean height in control lane

Percentage overlapping cover was measured using a point-quadrat method along two fixed lines (similar to that in Gallet and Roze 2001). At each of 76 points spread at $10 \mathrm{~cm}$ intervals along two transects in each lane, a long thin rod $(\sim 4 \mathrm{~mm})$ was lowered, and all life-forms (grass, other graminoids, shrubs and herbs) bare ground (no live or dead material touching rod) and litter (detached plant material), touching the rod were recorded. Where more than one species within the same life form touched the rod, separate hits were recorded for each species at that point. Relative cover for each category was then calculated using the following formula:

Relative cover $=$ contributing cover of category post trampling in a lane $\times c f$ initial cover of category in the control lane

Where: $c f$ (control factor) $=\underline{\text { initial cover in control lane }}$ cover in control lane post trampling Species richness was measured by recording all species in each lane 2 weeks post trampling.

\subsection{Data analysis}

The effect of trampling on relative height of all vegetation, relative vegetation cover, absolute vegetation cover of dominant life-form in each community and species richness was analysised using a Randomized Complete Block (RCB) design in the SPSS for windows 13.0 program. Treatment was included as a fixed variable whilst replicate-blocks were analysed as a random variable.

As it was expected that the control lanes would differ to the other treatment lanes an a priori test using contrasts was chosen. Thus, if low levels of trampling were not- 
significantly different to the controls, a contrast test would determine which levels of use may have caused vegetation damage.

A Resistance Index (the number of passes required to cause a $50 \%$ reduction in height or cover, Liddle, 1997) was calculated for each vegetation type either from text or from graphs of relative vegetation parameters and compared with published data (Supplementary Material 1).

\section{Results}

A total of 73 species were recorded of which 22 were introduced (e.g. not native to Australia, Supplementary Material 1). Although there was some overlap in species composition among the vegetation types (Cynodon dactylon and Lobelia purpurascens), they differed in cover of life forms, vegetation height, species richness per lane and overall composition (Supplementary Material 1, Table 2). All the vegetation parameters were significantly affected by trampling with the analysis conducted on relative height, relative cover and species richness revelling differences among treatments (Table 3).

\subsection{Vegetation height}

In the Fern understorey there was an immediate decline in height due to trampling (Table 3, Fig. 2a). The average height pre-trampling was $76 \mathrm{~cm}$ compared to $39 \mathrm{~cm}$ two weeks post trampling. In the Tussock grass understorey vegetation height declining from $25 \mathrm{~cm}$ to $12 \mathrm{~cm}$ post trampling (Fig. 2b). In the disturbed grassland vegetation height declined from $7 \mathrm{~cm}$ to $6 \mathrm{~cm}$ (Fig. 2c).

The lowest level of trampling to cause a significant reduction in relative height immediately post trampling, varied among the vegetation types (Fig. 2). In the Fern understorey, 10 passes caused a significant decline in relative vegetation height while 
in the Tussock grass understorey it required 25 passes before there was a significant impact. The Disturbed grassland showed the greatest resistance with 100 passes required before there was a significant reduction in relative height. The number of passes required to cause a $50 \%$ reduction in height followed a similar trend, requiring the lowest trampling intensity in the Fern understorey ( 90 passes), followed by the Tussock grass understorey ( 100 passes) while it required $\sim 400$ passes in the Disturbed grassland (Fig. 2).

\subsection{Vegetation cover}

Trampling reduced vegetation cover in all three vegetation types (Table 3, Fig. 3). The greatest decline was in the Fern understorey $63 \%$ of vegetation cover remaining post trampling compared to $72 \%$ in the Tussock grass understorey and $89 \%$ in the Disturbed grassland. In the Fern and Tussock grass understoreys, it took more passes to reduce vegetation cover than height (Table 3). There was a significant decline in vegetation cover at $>10$ passes in the Fern understorey (Fig. 3a), and 50 passes in the Tussock grass understorey (Fig. 3b), while in the Disturbed grassland it only took 10 passes (Fig. 3c). For the Fern understorey, a 50\% reduction in cover occurred after 210 passes, compared to 360 passes in the Tussock grass understorey and $~ 860$ passes in the Disturbed grassland (Fig. 3).

When the cover of the dominant life form in each community was examined (Fig. 4), there were also differences among vegetation types (Table 3). In the Fern understorey, the dominant Bracken Fern (Pteridium esculentum) declined in cover from 100 passes onwards, and had a resistance index of 260 passes (Tables 3 and 4, Fig. 4a). In the Tussock grass understorey, the dominant life form 'grass' (mostly Blady Grass - Imperata cylindrica, Couch - Cynodon dactylon and Poa sp.) declined in cover after 150 passes and had a resistance index of 360 (Tables 3 and 4, Fig. 4b). 
In the Disturbed grassland, cover only declined after 400 passes for the grasses (Slender Pigeon Grass - Setaria gracilis and Couch -Cynodon dactylon, Tables 3 and 4, Fig. 4c) with a resistance index of $\sim 1300$ passes. In contrast to the values for each of the dominant life-forms, the minor life-forms were sensitive to trampling and had much lower resistance index values (Table 4) Therefore, although some life forms may have only had a relatively small contribution to overall cover, they can have a large effect on the response of the community to trampling.

\subsection{Species richness}

Trampling resulted in significant declines in species richness in the three vegetation types two weeks following trampling (Table 3, Fig. 5). In the Fern understorey, there was a steady decline in species richness with increasing trampling intensity, with a significant decline apparent at only 10 passes (Fig. 5a). This is likely to be due to damage to small-leaved, low-growing herbs in this community which may be easily crushed even at low trampling intensity. Such species included the soft-leaved White Helmet-orchid (Corybas barbarae) and Wombat berry (Eustrephus latifolius) which had frequencies of $26 \%$ and 54\% respectively (Supplementary Material 1).

The Tussock grass understorey appears to be slightly more resistant, with significant declines in species richness from 25 passes onward (Fig. 5b). This community also contained many small herbs susceptible to crushing and searing due to trampling (Supplementary Material 1). However, it is possible that the grasses and graminoids which dominated in the overall species composition may have cushioned and protected the smaller herbs (Liddle, 1995). As a result, the resistance of the community as a whole may have been increased.

It was expected that the Disturbed grassland which was mainly dominated by tough low growing grasses principally the resistant, introduced Setaria gracilis and 
the native Bermuda grass (Supplementary Material 1), would be the most resistant community and hence have the smallest decline in species richness. The results support this hypothesis with consistent declines in species richness from 150 passes onwards (Fig. 5c). An exception was found in the 50 pass lane, which was also significant. After 500 passes, the $\sim 30 \%$ reduction in species richness in the Disturbed grassland was less than the $\sim 50 \%$ and $\sim 40 \%$ reductions in the Fern understorey and Tussock grass understorey respectively.

\section{Discussion}

\subsection{Effect of trampling on vegetation}

The resistances of three subtropical vegetation types in Australia to standardized trampling protocols varied as predicted based on results from studies in other continents and/or climatic zones. As expected, the upright growth form of fern was sensitive to trampling, with Bracken fern having vertical, woody and brittle stems and fibrous roots: characteristics typical of a low resistance species (Liddle, 1997; Yorks et al. 1997; Littlemore and Barker, 2003). In the subtropics in Australia only a few passes resulted in damage to vegetation height, vegetation cover and the cover of ferns. Although recovery, and hence tolerance was not assessed in this study, based on other studies (Liddle, 1997; Yorks et al. 1997; Littlemore and Barker, 2003), it is likely that this fern understorey would not only have low resistance but also slow to recover from trampling, and hence have low tolerance to this type of use.

The Tussock grass understorey was quite tall $(25 \mathrm{~cm})$ and dominated by tussock grasses and hence even a few passes reduced vegetation height. Although flattened, these grasses may not have been crushed and broken by trampling, and hence more passes were required to reduce vegetation cover than height. It is likely that this community may recover relatively fast from low levels of trampling, but higher use 
resulted in permanent damage to stems which might take longer to recover (Yorks et al. 1997). Overall it would appear likely to have moderate tolerance to trampling. The shorter $(8 \mathrm{~cm})$ Disturbed grassland required more passes to reduce vegetation with the shorter, matt forming grasses and graminoids tending to have high resistance, due to features such as flexible, horizontal stems, narrow leaves and high leaf strength (Sun and Liddle, 1993; Yorks et al. 1997). One of the dominant grasses in the Disturbed grassland, Couch (Cynodon dactylon, 81\%), was found to have high resistance in a Brisbane glasshouse experiment due to its high flexibility at the base of the stem (Sun and Liddle, 1993). This species is also likely to have fast recovery from damage, as it is used as a hardy lawn species and is commonly found in recreational areas that are regularly mown (Sun and Liddle, 1993). For example it was one of the most frequently recorded species in regular trampled sites in Costa Rica (Soccer fields), with no change in its cover even in areas of high use (Frenkel 1972).

\subsection{Resistance index}

To facilitate comparability among studies, vegetation types, a resistance index can be calculated, with the most commonly used index the number of passes required to cause a 50\% reduction in vegetation cover (or biomass, Liddle 1997). The three vegetation types here differed in resistance with the Fern understorey the least resistant, the Tussock grass understorey with moderate resistance, while the Disturbed grassland was among the top six most resistant vegetation types (Table 4 and Supplementary Material 2).

When resistance indices for different climatic zones, life-form and vegetation types are compared, some unexpected patterns emerge. For example, although the general pattern of resistance based on the dominant life-form is graminoids $>$ trees 
$>$ forbs >shrubs (Yorks et al. 1997), among the results for 55 vegetation types summarised here, the pattern followed graminoid $>$ shrub $>$ fern $>$ forb (Table 5). Correspondingly, although alpine, artic and subalpine vegetation types are considered to be particularly susceptible to trampling impacts (Liddle, 1997; Cole, 2004), they were more resistant than montane vegetation types, with the order of resistance following a subtropical $>$ alpine $\sim$ temperate $\sim$ subalpine $\sim$ arctic $>$ montane pattern (Table 5). For vegetation types the pattern was closer to predictions with the order of resistance following sand-dune grasslands > grasslands > sand dune heaths $>$ forest understorey $>$ heaths $\sim$ herbfields.

There was considerable variation in resistance within each dominant life-form, climatic zone and vegetation type indicating that these general grouping should not always be relied upon to predict resistance in a particular vegetation type. At least some of this variation may be due to the relative mixes of sensitive and more resistant species/life-forms within a vegetation type. In this study, for example, herbs had a large influence on the overall resistance index of the three vegetation types even though they did were not dominant any of them.

\subsection{Species richness}

Changes in species richness among the three vegetation types showed a similar pattern to the resistance index, with the Fern understorey and the Tussock grass understorey least resistant and the Disturbed grassland substantially more resistant. Although fewer studies have compared the number of passes required to affect species richness than vegetation cover, some comparisons can be made. In remnant woodland on the Israel coastal plains, the number of passes that caused significant losses in species richness was 300 passes (Kutiel et al. 2000). Even more resistant, were two alpine vegetation types in the Australian Alps, where it required more than 
500 passes to reduce species richness (Growcock, 2005). These values are much higher than for the current study. These differences may be due to the greater power in this study due to the larger number of replicates, or that other vegetation types do require more trampling before species richness is affected.

Prior to any trampling, there was substantial overlapping cover in the Fern understorey. This was significantly reduced at the lowest trampling levels. Under normal circumstances, beneath the fern, ground cover species would need to survive with reduced sunlight and relatively moist growing conditions. It is possible that the combination of exposure and trampling effects may have caused death of individuals, thus reducing species richness at low trampling intensity. In comparison, the matforming grasses in the Disturbed grassland may have actually protected low-growing typically sensitive herbs. The fern fronds tended to break, yet remain attached, thus failing to protect ground-cover herbs. Conversely, the flexible stems of the grasses, allowed cushioning of adjacent plants, potentially reducing direct impacts such as bruising and sheering of vegetative parts.

This study only looked at resistance and not resilience of these vegetation types. It is probable that the reliance of the three communities is similar to their resistance (Fern understorey $<$ Tussock grass understorey $<$ Disturbed grassland) based on the species/life-forms dominant in each type. It is also likely that these three subtropical communities may recover faster than communities in cold climates, reflecting general growth rate of plants in the different ecosystems. Certainly trampling in arctic/alpine vegetation is often characterised by low resistance and very slow recovery, with some impacts only becoming apparent months or even a year or more after use (Forbes et al. 2005)

\subsection{Implications for management}


The Coomabah Lakes Conservation Area is one of the few remnant areas of mostly undisturbed vegetation in the middle of the rapidly growing Gold Coast, the sixth largest city in Australia. Within this protected area, which is an internationally significant wetland, three vegetation types varied in their resistance, and probably their resilience, to trampling. For the Gold Coast City Council which is responsible for managing the area, it is clearly that they need to limit trampling in the fern understorey, and to a lesser extent in the tussock grassland, but not in the disturbed grassland.

\section{Conclusions}

This study highlights that although it is possible to make useful generalisations concerning the resistance of given vegetation types to trampling, there is also considerable variation in the impact of trampling on plants even within the same life form, vegetation type and climatic zone. Therefore, for areas of high conservation value, specific trampling trials may be necessary to determine which levels of use result in unacceptable damage.

\section{Acknowledgments}

Thanks to students and colleagues who assisted in the trampling trials. We particularly thank Michael Arthur for his statistical advice and Wendy Hill, Ralf Buckley, Guy Castley, Michael Arthur and three anonymous reviewers for providing editorial comments on the manuscript. This research was supported by the Sustainable Tourism Cooperative Research Centre, Griffith University.

\section{References}


Andres-Abellan, M., Lopez-Serrano, F.R., Garcia Morote, F.A., Del Cerro-Barja, A. 2006. Assessment of trampling simulation impacts on native vegetation in Mediterranean Sclerophyllous forest. Environmental Monitoring and Assessment, 120, 93-107.

Bell, K.L., Bliss, L.C. 1973. Alpine disturbance studies: Olympic National Park, USA. Biological Conservation, 5: 25-32.

Chappell, H.G., Ainsworth, J.F., Cameron, R.A.D., Redfern, M. 1971. The effect of trampling on a chalk grassland ecosystem. Journal of Applied Ecology 8, 869882.

Cole, D.N. 1995a. Experimental trampling of vegetation. I. Relationship between trampling intensity and vegetation response. Journal of Applied Ecology 32, 203214.

Cole, D.N. 1995b. Experimental trampling of vegetation. II. Predictors of resistance and resilience. Journal of Applied Ecology 32, 215-224.

Cole, D.N. 2004. Impacts of hiking and camping on soils and vegetation: a review. In: Buckley, R. (ed.). Environmental Impacts of Ecotourism CABI Publishing, Wellingford. pp. 41-60.

Cole, D.N., Bayfield, N.G. 1993. Recreational trampling of vegetation: standard experimental procedures. Biological Conservation 63, 209-215.

Cole, D.N., Monz, C.A. 2002. Trampling disturbance of high-elevation vegetation, Wind River Mountains, Wyoming, U.S.A. Arctic, Antarctic and Alpine Research 34, 365-375.

Cole, D.N., Spildie, D.R. 1998. Hiker, horse and llama trampling effects on native vegetation in Montana, USA. Journal of Environmental Management 53, 61-71.

Duffey, E. 1975. The effects of human trampling on the fauna of grassland litter. Biological Conservation 7, 255-274. 
Forbes, B., Tolvanen, A., Kaine, K., Wielgolaski, F.E. 2005. Rates and process of natural regeneration in disturbed habitats. In: Wielgolaski, F.E., Karlsson, P.S., Neuvonen, S., Thannheiser, D. (Eds), Plant Ecology, Herbivory, and Human Impact in Nordic Mountain Birch Forests. Springer-Verlag, Berlin, pp.193-202.

Frenkel, R.E. 1972. Trampling vegetation and floristic convergence in the tropics. Association of Pacific Coast Geography Yearbook 34, 87-98

Gallet, S. Roze, F. 2001. Resistance of Atlantic heathlands to trampling in Brittany (France): influence of vegetation type, season and weather conditions. Biological Conservation 97, 189-198.

Gallet, S., Lemauviel, S., Roze, F. 2004. Responses of three heathland shrubs to single or repeated experimental trampling. Environmental Management 33, 821829.

Growcock, A.J. 2005. Impacts of Camping and Trampling on Australian Alpine and Subalpine Vegetation. PhD Thesis, Griffith University, Gold Coast.

Kellomaki, S. 1973. Ground cover response to trampling in a spruce stand of Myrtillus type. Silva Fennica, 7, 96-113.

Kutiel, P., Eden, E., Zhevelev, Y. 2000. Effect of experimental trampling and offroad motorcycle traffic on soil and vegetation on stabilized coastal dunes, Israel. Environmental Conservation 27, 14-23.

Lemauviel, S., Roze, F. 2003. Response of three plant vegetation types to trampling in a sand dune system in Brittany (France). Environmental Management 31, 227237.

Liddle, M.J. 1997. Recreation Ecology. Chapman \& Hall, London.

Littlemore, J., Barker, S. 2001. The ecological response of forest ground flora and soils to experimental trampling in British urban woodlands. Urban Ecosystems 5, 257-276 
Marion, J.L., Cole, D.N. 1996. Spatial and temporal variation in soil and vegetation impacts on campsites. Ecological Applications 6, 520-530

Monz, C. 2002. The response of two arctic tundra plant communities to human trampling disturbance. Journal of Environmental Management 64, 207-217

Monz, C.A., Pokorny, T. Freilich, J., Kehoe, S., Ayers-Baumeister, D. 2000. The consequences of trampling disturbance in two vegetation types at the Wyoming Nature Conservancy's Sweetwater River Project Area. USDA Forest Service Proceedings RMRS-P_15 Volume 5, 153-159.

Newsome, D., Moore, S.A., Dowling, R.K. 2002. Natural Area Tourism: Ecology, Impacts and Management. Channel View Publications. Clevedon, United Kingdom.

Pickering, C.M., Hill, W. 2007. Impacts of recreation and tourism on plant biodiversity and vegetation in protected areas in Australia. Journal of Environmental Management. 85, 791-800.

PlantNet 2007. National Herbarium of New South Wales (1999-2005) New South Wales Flora Online National Herbarium of New South Wales, Royal Botanic Gardens \& Domain Trust, Sydney Australia (http://plantnet.rbgsyd.nsw.gov.au/) Visited in February 2007.

Roovers, P., Verheyen, K, Hermy, M., Gulinck, H. 2004. Experimental trampling and vegetation recovery in some forest and heathland communities. Applied Vegetation Science 7, 111-118.

Ros, M., Garcia, C. Hernandez, T., Andres, M., Barja, A. 2004. Short-term effects of human trampling on vegetation and soil microbial activity. Communications in Soil Science and Plant Analysis, 35; 1591-1603.

Sun, D., Liddle, M.J. 1993. Plant morphological characteristics and resistance to simulated trampling. Environmental Management 17, 511-521. 
Talbot, L.M., Turton, S.M., Graham, A.W. 2003. Trampling resistance of tropical rainforest soils and vegetation in the wet tropics of north east Australia. Journal of Environmental Management 69, 63-69.

Thurston, E., Reader, R.J. 2001. Impacts of experimentally applied mountain biking and hiking on vegetation and soils of a deciduous forest. Environmental Management 27, 397-409.

Tolvanen, A. Forbes, B., Rytkönen, K., Laine, K. 2001. Regeneration of dominant plants after short-term pedestrian trampling in sub-arctic plant communities. In Wielgolaski, F.E. (ed.) Nordic Mountain Birch Ecosystems. UNESCO, Paris. Pp. 356-368.

Torn, A., Rautio, J., Norokorpi, Y., Tolvanen, A. 2006. Revegetation after short-term trampling at subalpine heath vegetation. Annual Botanical Fennici 43, 129-138.

Weaver, T., Dale, D. 1978. Trampling effects of hikers, motorcycles and horses in meadows and forests. Journal of Applied Ecology, 15, 451-457.

Whinam, J., Chilcott, N. 1999. Impacts of trampling on alpine environments in Central Tasmania. Journal of Environmental Management 57, 205-220.

Whinam, J., Chilcott, N.M. 2003. Impacts after four years of experimental trampling on alpine/subalpine environments in western Tasmania. Journal of Environmental Management 67, 339-351.

Yorks, T.J., West, N.E., Mueller, R.J. Warren, S.D. 1997. Toleration of traffic by vegetation: Life form conclusions and summary extracts from a comprehensive data base. Environmental Management 21, 121-131. 